\title{
Flare-up of cytokines in rheumatoid arthritis and their role in triggering depression: Shared common function and their possible applications in treatment (Review)
}

\author{
CHUNHAI ZHANG \\ Thyroid Surgery Department, China-Japan Union Hospital of Jilin University, Changchun, Jilin 1300332, P.R. China
}

Received January 9, 2020; Accepted May 31, 2020

DOI: $10.3892 /$ br.2020.1392

\begin{abstract}
Chronic illnesses are associated with an increased risk of depression and anxiety. Rheumatoid arthritis (RA) is a chronic autoimmune disease that typically causes damage to the joints. RA extensively impacts patients, both physically and psychologically. Depression is a common comorbid disorder with RA, which leads to worsened health outcomes. There are several cytokines that are active in the joints of patients with RA. Inflammatory cytokines serve important roles in the key processes in the joints, which usually cause inflammation, articular damage and other comorbidities associated with RA. The key role of inflammatory cytokines could be attributed to their interactions within signaling pathways. In RA, IL-1, and the cytokines of TNF- $\alpha$, IL- 6 and IL-18 are primarily involved. Furthermore, depression is hypothesized to be strongly associated with systemic inflammation, particularly with dysregulation of the cytokine network. The present review summarizes the current state of knowledge on these two diseases from the perspective of inflammation and cytokines, and emphasizes the possible bridge between them by exploring the involvement of systemic cytokines in both conditions.
\end{abstract}

\section{Contents}

1. Rheumatoid arthritis and depression

2. Immunological pathology of RA

3. Inflammatory cytokines in RA

4. Anti-cytokine therapies in RA

5. Role of cytokines in depression: Mechanism and treatment

6. Conclusion

Correspondence to: Dr Chunhai Zhang, Thyroid Surgery Department, China-Japan Union Hospital of Jilin University, 126 Xian Tai Street, Changchun, Jilin 1300332, P.R. China

E-mail: chunhai@jlu.edu.cn

Key words: rheumatoid arthritis, inflammatory cytokines, depression, cytokine network

\section{Rheumatoid arthritis and depression}

Rheumatoid arthritis (RA) is a chronic autoimmune disease that typically causes damage to the joints. The disease primarily targets the synovial membrane, cartilage and bone. As a systemic inflammatory disease, RA also affects other tissues and organs, and is thus associated with progressive disability, potential systemic complications, high socioeconomic costs, and early death worldwide (1). Although, there have been advances in the understanding of the pathogenesis of RA, the cause of RA remains elusive (1). The pathogenesis of RA is complex and involves large numbers of different cell types and signaling pathways (2). It is widely accepted that autoimmune processes and cytokines may serve important roles in the initiation and perpetuation of the disease $(3,4)$. Among these, TNF, IL-6 and IL-1 are the best studied, and are further discussed in the following section. The current strategies for treatment of RA include symptomatic management and early disease therapy (5). As RA is an inflammatory disease, medications that suppress inflammation, such as non-steroidal anti-inflammatory drugs and glucocorticoids are frequently used as first-line therapeutic agents for treatment of the symptoms (6). During the last decade, disease-modifying antirheumatic drugs (DMARDs) were introduced as an important therapeutic strategy due their effect on the binding of pro-inflammatory cytokines to their corresponding receptors (7), and these should be initiated as soon as RA is diagnosed (8). The most commonly used biological DMARDs in RA therapy include inhibitors of TNF- $\alpha$ (infliximab, etanercept, adalimumab, golimumab and certolizumab pegol), IL-1 inhibitors, anti-IL-6 receptor monoclonal antibody (tocilizumab), the T-cell signaling inhibitor (abatacept) and the chimeric anti-CD20 monoclonal antibody (rituximab) (9). Patients started on combined treatment of conventional synthetic DMARDs with biological DMARDs in earlier stages showed obvious clinical improvement and less damage to the joints in the BeSt study (10).

Depression and anxiety are frequent comorbidities in patients with RA and it has been shown that they may occur in up to $42 \%$ in RA patients (11). It is estimated that $30 \%$ of patients with RA develop depression within 5 years of being diagnosed (12). Depression significantly and synergistically contributes to increased mortality and morbidity in patients with RA, and also increases health care costs for the health 
system (13). Inflammatory networks and cytokines may constitute a link between depression and RA. The co-occurrence of depression in RA is significantly associated with age, and younger patients show a higher risk of developing depression compared with older patients (12). Low self-esteem is among the strongest predictors in patients with RA who may eventually end up with depression (12). During the past two decades, the reciprocal communication between the central nervous system (CNS), endocrine system and immune system has been well established (14). Some of the psychiatric diseases, including depression, are hypothesized to be closely associated with systemic inflammation and cytokines. Therefore, exploring the common functions that may be shared by RA and depression will both broaden the horizon of basic research in these two fields and may also provide theoretical support for the clinical treatment of RA with a systemic view.

The aim of this review is to discuss the biological contribution and potential therapeutic targets of the major cytokine families in the aetiology of RA and depression, and summarize the complex pathophysiology of this disease with a focus on cytokines, including TNF- $\alpha$, IL- 6 and IL- 1 and their families and relevant signaling pathways. Furthermore, the therapeutic agents that are presently utilized in both of the diseases, along with potential therapeutic targets are reviewed. Additionally, how an improved understanding of the role of cytokines and signaling pathways in these two diseases may help the development of novel therapeutic strategies with specific targets is briefly discussed.

\section{Immunological pathology of RA}

Major histocompatibility complex (MHC) is considered a key factor associated with a predisposition to RA (15). Outside of the MHC region, additional risk loci have been identified and validated including PTPN22, STAT4, PADI4, CTLA4 and Fc $\gamma$ Rs, as well as various cytokine and cytokine-receptor loci. Several immune modulators (cytokines and effector cells) and signaling pathways involved in the pathophysiology of RA have been revealed. The complex interactions between the inflammatory cytokines are responsible for joint damage that is initiated at the synovial membrane and then progresses to other structures of the joint. There is extensive activation of monocytes, macrophages, and synovial fibroblasts, as well as overproduction of pro-inflammatory cytokines, such as IL-1, IL- 6 and TNF- $\alpha$ amongst others (16). There are other cytokines and chemokines that are also found in the synovial membrane, such as IL-15, IL-17 and IL-18. These inflammatory cytokines activate several signaling pathways and induce transcription of the genes, which are key factors involved in inflammation and tissue degradation (17). Due to the important roles of inflammatory cytokines in RA, there has been increasing interest in how the inflammatory cytokines within a complex regulatory network are associated with disease progression of RA.

\section{Inflammatory cytokines in RA}

Inflammatory cytokines are responsible for stimulating destructive mechanisms in the joint which results in structural injury and subsequently leads to a functional decline in mobility and disability.
Role of IL-1 and IL-18 in RA. IL-1 is an important inflammatory factor that is involved in the pathogenesis of RA. IL-1 induces an inflammatory response and activates or increases the expression of other pro-inflammatory mediators that promote damage to the joints (18). In the synovial membrane, IL-1 and IL-1 receptor antagonists are abundantly expressed (18). IL-1 activation causes migration of inflammatory cells to the joints and the synovium in patients with RA. Then, macrophages, lymphocytes, monocytes and transformed fibroblasts are triggered to produce increased quantities of IL-1, which contributes to the production and secretion of various cellular messengers (19). Regulatory agents, such as proteoglycans and proteases contribute to the formation and accumulation of pannus in the joints, resulting in the erosion of the cartilage and bone, fibrosis, and ultimately articular function loss (20). At the cellular level, there are several other cytokines induced by IL-1, including TNF- $\alpha$ and IL-6 (18). As the key pro-inflammatory cytokines in RA, IL-1 and TNF- $\alpha$ act synergistically in promoting further inflammation and matrix damage to the arthritic joints (21). In an experimental animal model, IL-1 was shown to stimulate cartilage and bone re-absorption and inhibit articular collagen and proteoglycan synthesis (22). Experiments performed on RA animal models suggest that IL-1 serves a crucial role in the degradation of proteoglycans and thus increases joint damage $(22,23)$. Local production of IL-1 was shown to inhibit proteoglycan synthesis in the knee joints of a collagen-induced arthritis (CIA) model (24). In addition, IL-6 in synovial cells can lead to the acceleration of joint breakdown by attracting and retaining large quantities of leukocytes in the inflamed synovium (25). In patients with RA, there are increased levels of IL-1 in the plasma and synovial fluid $(26,27)$. The IL-1 family includes IL-1 $\alpha$ and IL-1 and IL1 receptor antagonist (IL-1Ra). The biological activation of cells by IL-1 requires the expression of the type I IL-1 receptor (IL-1R). The receptor antagonist IL-1Ra, generated by certain cells in the joint, can competitively bind with IL-1R. As an anti-inflammatory protein that binds to IL-1R without transducing signals, IL-1Ra may, to some extent, regulate the activity of IL-1 (18). It has been reported that IL-1Ra-deficient mice develop spontaneous arthritis, mediated through the amplification of Th17-dependent inflammation (28). IL-1Ra effectively attenuated joint destruction in an experimental RA model (29). There is a dysregulation of IL-1Ra production and inhibition of the effects of IL-1 $\beta$ in RA patients (30). IL-18, another member of the IL-1 cytokine superfamily, is widely detected in the synovium of patients with RA (18). The mRNA expression levels of IL-18 and IL-1 $\beta$ are differentially regulated. It has been found that IL-18 distributes in the synovial membrane with a different pattern compared with IL-1 $\beta$. While IL-1 $\beta$ is localized primarily throughout the interstitium, lining layer and vasculature, IL-18 is highly expressed in lymphocytic aggregates (31). The expression of IL-18 in synovial tissues in vitro is associated with increased TNF- $\alpha$ and IL-1 $\beta$, and the blockade of IL-18 by a neutralizing antibody was shown to ameliorate the disease in rodent RA models (32). IL-18 also contributes to cartilage degradation by affecting cell proliferation and the expression of matrix metalloproteinase and inducible NO synthase gene expression (33). 
Role of IL-6 in RA. IL-6, which was initially identified as a $B$ cell regulatory factor, is now recognized as a soluble mediator with a pleiotropic function on inflammation, immune response, and hematopoiesis (34). It serves important roles in RA pathogenesis via the activation and maturation of $\mathrm{B}$ and $\mathrm{T}$ cells, as well as the production of autoantibodies. IL- 6 can stimulate $B$ and $T$ cell functions via promoting the proliferation of plasmablastic precursors in the bone marrow, maturating the immunoglobulin-producing plasma cells and through its role in $\mathrm{T}$ cell activation and proliferation (35). Although certain cytokines work on target cells that are close to their secretion site, IL-6 exerts its effects on distant target cells through ubiquitously expressed receptors. Classical IL- 6 signaling requires a protein complex that includes a membrane-bound, non-signaling $\alpha$-receptor unit (IL-6R) and two signal-transducing glycoprotein 130 (gp130) subunits (36). Conversely, IL-6 trans-signaling involves binding between a soluble receptor (sIL-6R) and membrane-bound gp130 subunits (36). As IL-6R expression is restricted to only a few cell types, trans-signaling leads to an increase in the range of IL-6-responsive cells (36). IL-6 trans-signaling is one of the major factors involved in the pathogenesis of RA. It is hypothesized that the increased IL-6 bioactivity is responsible for the local and systemic effects of RA. It seems that IL-6 acts as a major mediator of the acute phase response in RA (36). IL-6 is a 26-kDa pleiotropic cytokine, encoded on chromosome 7 , and is produced by various cell types, including $\mathrm{T}$ cells and B cells (36). It has been reported that IL- 6 is one of the most abundantly expressed inflammatory cytokines in the rheumatoid synovium (37). The concentration of IL-6 and sIL6R is correlated with the histological changes of chronic synovitis in patients with RA, while localized increases in sIL-6R are correlated with leukocyte infiltration (38). Vascular endothelial growth factor (VEGF) is a potent angiogenic factor that promotes the migration and proliferation of endothelial cells (39). VEGF also induces vascular permeability and mediates inflammation. IL- 6 was found to enhance joint inflammation and damage in patients with RA by affecting VEGF expression (40). IL-6 knockout mice were protected from CIA and exhibited reduced immune cell responses and tissue damage of knee joints $(34,41)$. IL-6 receptor blocking can ameliorate joint disease in murine CIA (34).

Role of TNF- $\alpha$ in RA.TNF- $\alpha$ is a pleiotropic, pro-inflammatory cytokine and is considered to serve a key role in the pathophysiological processes of RA. TNF- $\alpha$ is a ligand of the TNF superfamily (42). TNF- $\alpha$ is inserted into the cell membrane, and the extracellular portion is subsequently released into circulation (43). There are two distinct membrane receptors that have been identified and cloned, namely TNF-R1 and TNF-R2. The apparent molecular weight between the two receptors varies because of the variation in glycosylation. These receptors can bind to both the soluble and membrane-bound forms of TNF- $\alpha$ (44). TNF-R1 is responsible for the majority of the cellular responses to TNF- $\alpha$ (44). The ubiquitous expression of TNF-R, along with cell-specific effector molecules triggered by TNF-R contribute to the various effects of TNF- $\alpha$ including apoptosis, the synthesis of protein and lipid inflammatory molecules, and transcription factors (45). TNF- $\alpha$ contributes to activation of other inflammatory cytokines, including IL-1, IL-6, IL-8, and granulocyte-macrophage colony-stimulating factor (GM-CSF) (46). In an in vitro study, blocking TNF- $\alpha$ decreased the levels of IL-1, IL-6, IL-8, and GM-CSF in cultured synovial cells from RA patients (47). Thus, blockade of TNF- $\alpha$ may exert a more comprehensive effect on inflammation than other cytokines, such as IL-1, due to its high concentration in the synovial fluids. TNF- $\alpha$ is suggested to serve a key role in rheumatoid synovitis. In a CIA model, it was reported that TNF- $\alpha$ levels were elevated early in the disease course of CIA and persisted at high levels throughout the later stages (48). Mice with downregulated TNF- $\alpha$ expression developed chronic symmetric polyarthritis with histological features similar to that in human RA $(49,50)$.

\section{Anti-cytokine therapies in RA}

Recent developments in understanding the role of cytokines in the pathological changes of RA, combined with biopharmaceutical progress, have facilitated the development of novel treatments.

Anti-TNF- $\alpha$ agents in RA. Studies have shown that blockade of TNF appears to be the major breakthrough in RA treatment, and that TNF- $\alpha$ antagonists significantly reduce the symptoms of RA in patients $(51,52)$. Clinical studies have shown that the efficacy of the TNF inhibitors is at least comparable to methotrexate, which is one of the most effective medications currently used to treat RA (53). Long-term anti-TNF- $\alpha$ treatment reversed endothelial dysfunction in RA (54). A recent review indicated that TNF- $\alpha$ antagonists can ameliorate the progression of atherosclerosis and arterial changes $(21,55)$. The drugs currently available in the clinical practice and clinical trials are biological protein-based drugs, such as antibodies to TNF- $\alpha$ or agents targeting TNF- $\alpha$ receptors (for example, linked to Fc dimers) (56). There are five TNF- $\alpha$ inhibitors that have been approved for treatment of RA, including infliximab, etanercept, adalimumab, certolizumab and golimumab $(57,58)$. Their practical use has been limited by the need for repeated injections and other side effects (59). A recent large US observational study has also raised concerns regarding the risk of skin cancer with the use of biological therapy (60).

Anti-IL-1 agent in RA. Blocking of IL-1 has been considered as a potential strategy for treating RA. Anakinra, a recombinant form of human IL-1R antagonist, appears to inhibit the proinflammatory effect of IL-1 (18). It is identical to the natural endogenous IL-1RA form (61). Due to its short half-life, daily injections are required. Anakinra decreases the migration of immune cells into the joint of patients with RA (62). In RA patients, joint damage is significantly attenuated following anakinra treatment (63). The most commonly observed adverse effect of anakinra is the susceptibility to infections and skin irritation at the injection site (64). However, due to the inconvenience of daily injections of anakinra and the superior clinical effects of other anti-cytokine therapies, anakinra is not used as a first-line treatment in RA $(63,64)$.

Anti-IL-6 agent in RA. A monoclonal antibody, Tocilizumab (TCZ) binds to IL-6R and the binding subsequently blocks 
dimerization of the receptor complex, preventing IL-6 transmembrane signaling (65). The efficacy of TCZ in the treatment of RA has been confirmed in a few clinical trials $(66,67)$. Reducing IL-6 activity in the inflammatory process of RA prevents inflammation of the joints, decreases damage, and reduces certain systemic symptoms $(68,69)$. The erosion in joint and space narrowing were significantly decreased in TCZ treated patients compared with the DMARD treated group, suggesting that the inhibition of IL- 6 was effective in both managing the symptoms and sustaining structural integrity of the joints (70). Similar to other disease modifying drugs, safety is always a major concern when investigating a new line of therapies (71). Further studies are required to examine the treatment benefits of TCZ therapy in RA treatment (68).

Upcoming therapies for $R A$. There are several potentially promising therapies targeting cytokines in RA which are being studied and may serve as suitable novel therapies for RA treatment. IL-18 may be a novel target for treating patients with RA. Recombinant IL-18 binding protein treatment abrogated disease severity (29), and treatment of anti-IL-18 in mice with collagen-induced arthritis exhibited similar results (29). IL-10 and IL-4 are cytokines with opposing-regulatory roles, both of which could downregulate pro-inflammatory responses. IL-10 and IL-4 are suggested to suppress the generation of inflammatory cytokines including IL-1, IL- 6 and TNF- $\alpha$ in RA. A recent study on Janus kinase (JAK) inhibitors demonstrated that the JAK/STAT signalling pathway mediated cytokines important for disease by facilitating the downstream signaling cascade of cytokine receptors upon binding with their respective cytokines, such as by increasing transcription of certain genes (72). For example, tofacitinib, a typical JAK inhibitor that interferes with the JAK-STAT signaling pathway and mRNA transcription, is currently used for the treatment of RA. Previous studies have shown that stimulation with IFNs results in STAT activation $(73,74)$. Table I summarizes the available anti-cytokine agents for treatment of RA.

\section{Role of cytokines in depression: Mechanism and treatment}

IL-6 in depression. It has previously been shown that IL-6 is associated with stress-related disorders, including depression and anxiety (75). A meta-analysis showed that IL-6 is the most significantly increased cytokine in the serum of depressed patients, and thus IL-6 levels in the serum may serve as a promising predictive biomarker for diagnosis of depression (75). Interestingly, a paediatric study found that peripheral inflammation predicted the occurrence of depression in younger patients (76). Children aged 9 with higher levels of IL- 6 demonstrated a $10 \%$ increased likelihood of suffering depression at the age of 18 compared with children with lower levels of IL-6. This result suggests that monitoring the blood IL-6 levels in younger patients at a high risk of depression during the early stages may be used to implement measures which would prevent the progression of deterioration of a patient's mood. Furthermore, several monoclonal antibodies are currently in clinical trials for their use in the possible treatment of mood disorders, such as chimeric
Table I. Anti-cytokine based therapeutic options for treatment of rheumatoid arthritis.

\begin{tabular}{lcc}
\hline Anti TNF- $\alpha$ agents & Anti IL-1 agent & Anti IL-6 agent \\
\hline Infliximab & Anakinra & Tocilizumab \\
Etanercept & \\
Adalimumab & \\
Certolizumab & & \\
Golimumab & &
\end{tabular}

IL, interleukin; TNF- $\alpha$, tumor necrosis factor- $\alpha$.

IL-6 receptor antibodies (Tocilizumab) or IL-6 antibodies (Siltuximab/Sirukumab) (75).

IL-1 in depression. It is well-established that the hippocampus is one of the key brain regions involved in the pathophysiology of depression (77). Stress and other environmental factors impact the functions of neurons in the hippocampus and influences depressive and anxiety-like phenotypes (77). Among the IL-1 cytokines, IL-1 $\beta$ is considered a key mediator responding to stressors, and it is widely expressed in the $\mathrm{CNS}$, including the hypothalamus, hippocampus, and cerebral cortex. A previous study showed that the levels of IL-1 $\beta$ in the blood serum and in the cerebrospinal fluid are increased in patients with significantly more stressful lives and in patients who suffer from depression $(78,79)$. Furthermore, the expression levels of IL-1 $\beta$ in peripheral blood circulation of patients with depression is correlated with the severity and duration of depression (77).

TNF- $\alpha$ in depression. Chronic illnesses induce the release of peripheral cytokines, which may result in cerebral endothelial leakage and then cause a neuroinflammatory reaction (80). The induced inflammatory response in the CNS is associated with the development of depression (81). TNF- $\alpha$ levels may be increased in patients who suffer from depression and is a potential biomarker for diagnosis of depression (82). In a pre-clinical study based on an animal model, deletion of TNF- $\alpha$ receptors was associated with antidepressant-like effects in behavioural tests compared with the wild-type counterparts (83). Additionally, a previous study showed that inhibiting the TNF- $\alpha$ signaling pathway may serve as a novel means of investigating how the CNS inflammatory response is associated with depression (81). Compounds targeting TNF- $\alpha$ signaling through inhibition of its downstream effectors exert anti-depressant and anti-anxiety-like effects in an animal model (81).

Other cytokines involved in depression. Interestingly, a recent study found that the antidepressant venlafaxine could ameliorate arthritis by targeting STAT3 and IL17 (84). Clinical data has validated that IFN- $\gamma$ levels are well correlated with clinical symptoms of depression in patients with glioma (85). Although there is no effort to explore whether IFN- $\gamma$ activated the STAT cascade in depression, data have shown that IFN- $\alpha$ can activate JNK/STATs in a model of depression (86). 


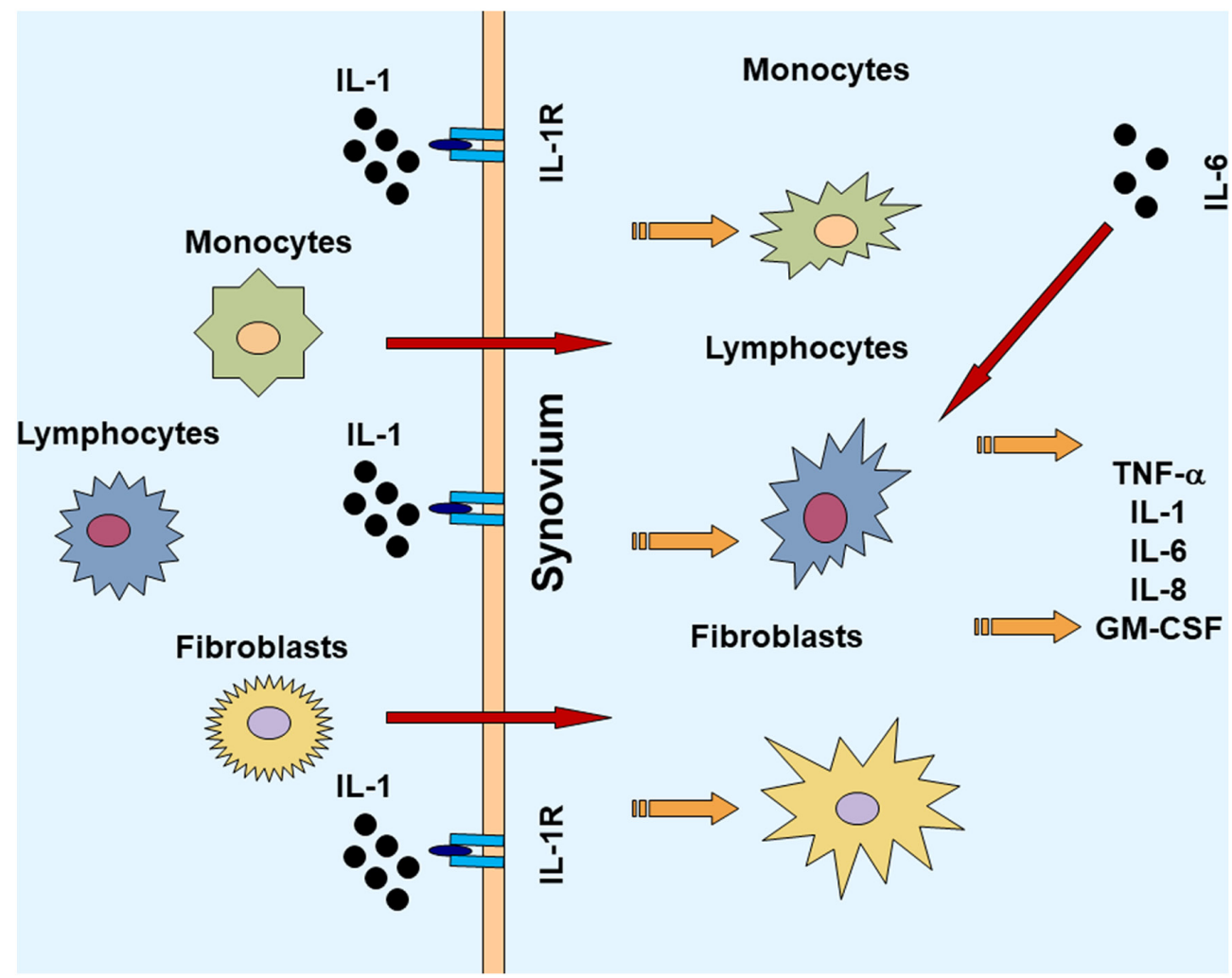

Figure 1. Role of activated lymphocytes, monocytes, fibroblasts in the pathogenesis of rheumatoid arthritis. IL, interleukin; GM-CSF, granulocyte-macrophage colony-stimulating factor; TNF- $\alpha$, tumor necrosis factor- $\alpha$.

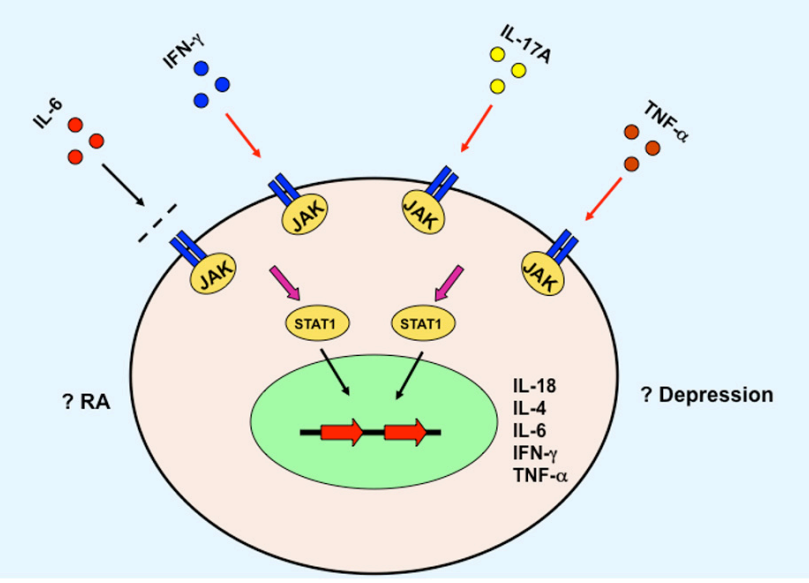

Figure 2. JAK/STAT3 signaling pathway mediates the role of cytokines. JAK, Janus kinase; IFN- $\gamma$, interferon- $\gamma$; IL, interleukin; TNF- $\alpha$, tumor necrosis factor- $\alpha$; RA, rheumatoid arthritis.

\section{Conclusion}

The pathogenesis of RA is complicated. It involves several immune cells and the interplay between numerous cytokines (Fig. 1) (87,88). Consequently, these cytokines further activate and promote differentiation of the downstream cells, which could result in local or systemic symptoms relevant to RA. For example, certain cytokines activate the JAK/STAT signaling pathway and initiate gene transcription of various other cytokines (Fig. 2) (89,90), and/or activate the

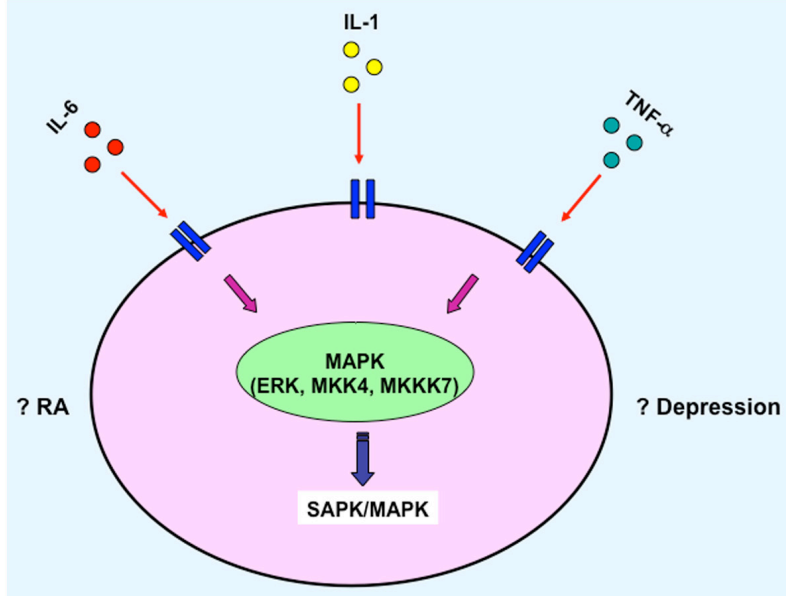

Figure 3. SPAK/MAPK signaling pathway mediates the role of cytokines. IL, interleukin; TNF- $\alpha$, tumor necrosis factor- $\alpha$; RA, rheumatoid arthritis.

SAPK/MAPK (Fig. 3) (91,92). Furthermore, depression is a frequently observed complication in patients with later stage RA. These two diseases may aggravate each other in via unknown mechanisms and afflict the patients further. This review focused on the inflammatory cytokines and signaling pathways which may serve as potential mediators of common pathways between RA and depression. One of the purposes of this review was to identify potential common therapeutic targets for both RA and depression treatment. With the encouraging preclinical and clinical data, there may be progress in therapeutic advancement targeting the unresolved 
clinical hurdles in RA with depression. To further elucidate the role of inflammation on the pathology of these diseases, and to design improved treatments, comprehensive analyses of mechanisms of action are necessary to optimise therapy with the ultimate focus of providing a cure for patients with these chronic illnesses. Additionally, RA is a chronic disease that is potentially devastating for a patient's quality of life and may result in mental disorders. Therefore, psychological factors may also be another key network responsible for the depression and other mood disorders in patients with RA.

\section{Acknowledgements}

Not applicable.

\section{Funding}

This review was supported by a Fellowship from China Scholarship Council for the support of his overseas research at the University of Manitoba (Canada).

\section{Availability of data and materials}

Not applicable.

\section{Authors' contributions}

$\mathrm{CZ}$ wrote and revised the manuscript. The author read and approved the final manuscript.

\section{Ethics approval and consent to participate}

Not applicable.

\section{Patient consent for publication}

Not applicable.

\section{Competing interests}

The authors declare that they have no competing interests.

\section{References}

1. Brennan FM and McInnes IB: Evidence that cytokines play a role in rheumatoid arthritis. J Clin Invest 118: 3537-3545, 2008.

2. Ungethuem U, Haeupl T, Witt H, Koczan D, Krenn V, Huber H, von Helversen TM, Drungowski M, Seyfert C, Zacher J, et al: Molecular signatures and new candidates to target the pathogenesis of rheumatoid arthritis. Physiol Genomics 42A: 267-282, 2010.

3. Nixon R, Bansback N and Brennan A: The efficacy of inhibiting tumour necrosis factor alpha and interleukin 1 in patients with rheumatoid arthritis: A meta-analysis and adjusted indirect comparisons. Rheumatology (Oxford) 46: 1140-1147, 2007.

4. Verhoef LM, van den Bemt BJ, van der Maas A, Vriezekolk JE, Hulscher ME, van den Hoogen FH, Jacobs WC, van Herwaarden N and den Broeder AA: Down-titration and discontinuation strategies of tumour necrosis factor-blocking agents for rheumatoid arthritis in patients with low disease activity. Cochrane Database Syst Rev 5: CD010455, 2019.

5. Upchurch KS and Kay J: Evolution of treatment for rheumatoid arthritis. Rheumatology (Oxford) 51: vi28-vi36, 2012.

6. Quan LD, Thiele GM, Tian J and Wang D: The development of novel therapies for rheumatoid arthritis. Expert Opin Ther Pat 18: 723-738, 2008.
7. O'Dell JR: Therapeutic strategies for rheumatoid arthritis. N Engl J Med 350: 2591-2602, 2004.

8. Mori S: Management of rheumatoid arthritis patients with interstitial lung disease: Safety of biological antirheumatic drugs and assessment of pulmonary fibrosis. Clin Med Insights Circ Respir Pulm Med 9 (Suppl 1): S41-S49, 2015.

9. Klarenbeek NB, Güler-Yüksel M, van der Kooij SM, Han KH, Ronday HK, Kerstens PJ, Seys PE, Huizinga TW, Dijkmans BA and Allaart CF: The impact of four dynamic, goal-steered treatment strategies on the 5-year outcomes of rheumatoid arthritis patients in the BeSt study. Ann Rheum Dis 70: 1039-1046, 2011.

10. Inui $\mathrm{K}$ and Koike $\mathrm{T}$ : Combination therapy with biologic agents in rheumatic diseases: Current and future prospects. Ther Adv Musculoskelet Dis 8: 192-202, 2016.

11. Bruce TO: Comorbid depression in rheumatoid arthritis: Pathophysiology and clinical implications. Curr Psychiatry Rep 10: 258-264, 2008.

12. Jacob L, Rockel T and Kostev K: Depression risk in patients with rheumatoid arthritis in the United Kingdom. Rheumatol Ther 4: 195-200, 2017.

13. Margaretten M, Julian L, Katz P and Yelin E: Depression in patients with rheumatoid arthritis: Description, causes and mechanisms. Int J Clin Rheumtol 6: 617-623, 2011.

14. Schiepers OJ, Wichers MC and Maes M: Cytokines and major depression. Prog Neuropsychopharmacol Biol Psychiatry 29: 201-217, 2005.

15. Viatte S, Plant D and Raychaudhuri S: Genetics and epigenetics of rheumatoid arthritis. Nat Rev Rheumatol 9: 141-153, 2013.

16. McInnes IB and Schett G: Cytokines in the pathogenesis of rheumatoid arthritis. Nat Rev Immunol 7: 429-442, 2007.

17. Firestein GS: Evolving concepts of rheumatoid arthritis. Nature 423: 356-361, 2003.

18. Kinne RW, Stuhlmüller B and Burmester GR: Cells of the synovium in rheumatoid arthritis. Macrophages. Arthritis Res Ther 9: 224, 2007.

19. Kinne RW, Bräuer R, Stuhlmüller B, Palombo-Kinne E and Burmester GR: Macrophages in rheumatoid arthritis. Arthritis Res 2: 189-202, 2000.

20. Hata H, Sakaguchi N, Yoshitomi H, Iwakura Y, Sekikawa K, Azuma Y, Kanai C, Moriizumi E, Nomura T, Nakamura T and Sakaguchi S: Distinct contribution of IL-6, TNF-alpha, IL-1, and IL-10 to $\mathrm{T}$ cell-mediated spontaneous autoimmune arthritis in mice. J Clin Invest 114: 582-588, 2004.

21. Schett $\mathrm{G}$ and Gravallese E: Bone erosion in rheumatoid arthritis: Mechanisms, diagnosis and treatment. Nat Rev Rheumatol 8: 656-664, 2012

22. Silveira KD, Coelho FM, Vieira AT, Barroso LC, Queiroz-Junior CM, Costa VV, Sousa LF, Oliveira ML, Bader M, Silva TA, et al: Mechanisms of the anti-inflammatory actions of the angiotensin type 1 receptor antagonist losartan in experimental models of arthritis. Peptides 46: 53-63, 2013.

23. Ruscitti P, Cipriani P, Liakouli V, Carubbi F, Berardicurti O, Di Benedetto P, Ciccia F, Guggino G, Alvaro S, Triolo G and Giacomelli R: The emerging role of IL-1 inhibition in patients affected by rheumatoid arthritis and diabetes. Rev Recent Clin Trials 13: 210-214, 2018.

24. Zou Y,Zeng S, Huang M, Qiu Q, Xiao Y, Shi M, Zhan Z, Liang L, Yang $\mathrm{X}$ and $\mathrm{Xu} \mathrm{H}$ : Inhibition of 6-phosphofructo-2-kinase suppresses fibroblast-like synoviocytes-mediated synovial inflammation and joint destruction in rheumatoid arthritis. Br J Pharmacol 174: 893-908, 2017.

25. Buckley CD: Michael Mason prize essay 2003. Why do leucocytes accumulate within chronically inflamed joints? Rheumatology (Oxford) 42: 1433-1444, 2003.

26. Kay J and Calabrese L: The role of interleukin-1 in the pathogenesis of rheumatoid arthritis. Rheumatology (Oxford) 43 (Suppl 3): iii2-iii9, 2004.

27. Arend WP, Palmer G and Gabay C: IL-1, IL-18, and IL-33 families of cytokines. Immunol Rev 223: 20-38, 2008.

28. Nakae S, Saijo S, Horai R, Sudo K, Mori S and Iwakura Y: IL-17 production from activated $\mathrm{T}$ cells is required for the spontaneous development of destructive arthritis in mice deficient in IL-1 receptor antagonist. Proc Natl Acad Sci USA 100: 5986-5990, 2003.

29. Abramson SB and Amin A: Blocking the effects of IL-1 in rheumatoid arthritis protects bone and cartilage. Rheumatology (Oxford) 41: 972-980, 2002.

30. Jacques C, Gosset M, Berenbaum F and Gabay C: The role of IL-1 and IL-1Ra in joint inflammation and cartilage degradation. Vitam Horm 74: 371-403, 2006. 
31. Lebre MC, Jongbloed SL, Tas SW, Smeets TJ, McInnes IB and Tak PP: Rheumatoid arthritis synovium contains two subsets of CD83-DC-LAMP-dendritic cells with distinct cytokine profiles. Am J Pathol 172: 940-950, 2008

32. Plater-Zyberk C, Joosten LA, Helsen MM, Sattonnet-Roche P, Siegfried C, Alouani S, van De Loo FA, Graber P, Aloni S, Cirillo R, et al: Therapeutic effect of neutralizing endogenous IL-18 activity in the collagen-induced model of arthritis. J Clin Invest 108: 1825-1832, 2001.

33. Lotz M: The role of nitric oxide in articular cartilage damage. Rheum Dis Clin North Am 25: 269-282, 1999.

34. Tanaka T, Narazaki $M$ and Kishimoto T: IL-6 in inflammation, immunity, and disease. Cold Spring Harb Perspect Biol 6 : a016295, 2014.

35. Alonzi T, Fattori E, Lazzaro D, Costa P, Probert L, Kollias G, De Benedetti F, Poli V and Ciliberto G: Interleukin 6 is required for the development of collagen-induced arthritis. J Exp Med 187: 461-468, 1998

36. Kishimoto T: Interleukin-6: From basic science to medicine-40 years in immunology. Annu Rev Immunol 23: 1-21, 2005

37. Narazaki M, Tanaka $\mathrm{T}$ and Kishimoto T: The role and therapeutic targeting of IL-6 in rheumatoid arthritis. Expert Rev Clin Immunol 13: 535-551, 2017.

38. Marrelli A, Cipriani P, Liakouli V, Carubbi F, Perricone C, Perricone R and Giacomelli R: Angiogenesis in rheumatoid arthritis: A disease specific process or a common response to chronic inflammation? Autoimmun Rev 10: 595-598, 2011.

39. Johnson KE and Wilgus TA: Vascular endothelial growth factor and angiogenesis in the regulation of cutaneous wound repair Adv Wound Care (New Rochelle) 3: 647-661, 2014.

40. Sokolove J and Lepus CM: Role of inflammation in the pathogenesis of osteoarthritis: Latest findings and interpretations. Ther Adv Musculoskelet Dis 5: 77-94, 2013.

41. Diaz-Torne C, Ortiz MDA, Moya P, Hernandez MV, Reina D, Castellvi I, De Agustin JJ, Fuente D, Corominas H, Sanmarti R, et al: The combination of IL-6 and its soluble receptor is associated with the response of rheumatoid arthritis patients to tocilizumab. Semin Arthritis Rheum 47: 757-764, 2018.

42. Aggarwal BB: Signalling pathways of the TNF superfamily: A double-edged sword. Nat Rev Immunol 3: 745-756, 2003.

43. Holnthoner W, Bonstingl C, Hromada C, Muehleder S, Zipperle J, Stojkovic S, Redl H, Wojta J, Schöchl H, Grillari J, et al: Endothelial cell-derived extracellular vesicles size-dependently exert procoagulant activity detected by thromboelastometry. Sci Rep 7: 3707, 2017.

44. Horiuchi T, Mitoma H, Harashima S, Tsukamoto $\mathrm{H}$ and Shimoda T: Transmembrane TNF-alpha: Structure, function and interaction with anti-TNF agents. Rheumatology (Oxford) 49: $1215-1228,2010$

45. Chen X and Oppenheim JJ: Contrasting effects of TNF and anti-TNF on the activation of effector T cells and regulatory $\mathrm{T}$ cells in autoimmunity. FEBS Lett 585: 3611-3618, 2011.

46. Yamagishi S, Ohnishi $M$ and Pawankar R: IL-1 and TNF-alpha-mediated regulation of IL-6, IL-8, and GM-CSF release from cultured nasal epithelial cells. Nihon Jibiinkoka Gakkai Kaiho 103: 829-835, 2000 (In Japanese).

47. Fiocco U, Sfriso P, Oliviero F, Lunardi F, Calabrese F, Scagliori E Cozzi L, Di Maggio A, Nardacchione R, Molena B, et al: Blockade of intra-articular TNF in peripheral spondyloarthritis: Its relevance to clinical scores, quantitative imaging and synovial fluid and synovial tissue biomarkers. Joint Bone Spine 80: $165-170,2013$

48. Bevaart L, Vervoordeldonk MJ and Tak PP: Evaluation of therapeutic targets in animal models of arthritis: How does it relate to rheumatoid arthritis? Arthritis Rheum 62: 2192-2205, 2010.

49. Monach PA, Benoist $C$ and Mathis D: The role of antibodies in mouse models of rheumatoid arthritis, and relevance to human disease. Adv Immunol 82: 217-248, 2004.

50. Hassan S, Milman U, Feld J, Eder L, Lavi I, Cohen S and Zisman D: Effects of anti-TNF- $\alpha$ treatment on lipid profile in rheumatic diseases: An analytical cohort study. Arthritis Res Ther 18: 261, 2016

51. Ma X and Xu S: TNF inhibitor therapy for rheumatoid arthritis Biomed Rep 1: 177-184, 2013.

52. Bourne T, Fossati G and Nesbitt A: A PEGylated Fab' fragment against tumor necrosis factor for the treatment of Crohn disease: Exploring a new mechanism of action. BioDrugs 22: 331-337, 2008.
53. Capria A, De Nardo D, Baffetti FR, Barbini U, Violo A, Tondo T and Fontana L: Long-term anti-TNF-alpha treatments reverse the endothelial dysfunction in rheumatoid arthritis: The biological coherence between synovial and endothelial inflammation. Int J Immunopathol Pharmacol 23: 255-262, 2010.

54. Tam LS, Kitas GD and Gonzalez-Gay MA: Can suppression of inflammation by anti-TNF prevent progression of subclinical atherosclerosis in inflammatory arthritis? Rheumatology (Oxford) 53: 1108-1119, 2014

55. Moelants EA, Mortier A, Van Damme J and Proost P: Regulation of TNF- $\alpha$ with a focus on rheumatoid arthritis. Immunol Cell Biol 91: 393-401, 2013.

56. Lis K, Kuzawińska O and Balkowiec-Iskra E: Tumor necrosis factor inhibitors-state of knowledge. Arch Med Sci 10: 1175-1185, 2014.

57. Radner $\mathrm{H}$ and Aletaha D: Anti-TNF in rheumatoid arthritis: An overview. Wien Med Wochenschr 165: 3-9, 2015.

58. van Schouwenburg PA, Rispens $\mathrm{T}$ and Wolbink GJ Immunogenicity of anti-TNF biologic therapies for rheumatoid arthritis. Nat Rev Rheumatol 9: 164-172, 2013.

59. Dommasch E and Gelfand JM: Is there truly a risk of lymphoma from biologic therapies? Dermatol Ther 22: 418-430, 2009.

60. Wolfe F and Michaud K: Biologic treatment of rheumatoid arthritis and the risk of malignancy: Analyses from a large US observational study. Arthritis Rheum 56: 2886-2895, 2007.

61. Bullock J, Rizvi SAA, Saleh AM, Ahmed SS, Do DP, Ansari RA and Ahmed J: Rheumatoid arthritis: A brief overview of the treatment. Med Princ Pract 27: 501-507, 2018

62. Kalliolias GD and Liossis SN: The future of the IL-1 receptor antagonist anakinra: From rheumatoid arthritis to adult-onset Still's disease and systemic-onset juvenile idiopathic arthritis. Expert Opin Investig Drugs 17: 349-359, 2008.

63. Ramírez J and Cañete JD: Anakinra for the treatment of rheumatoid arthritis: A safety evaluation. Expert Opin Drug Saf 17: 727-732, 2018.

64. Bresnihan B, Newmark R, Robbins S and Genant HK: Effects of anakinra monotherapy on joint damage in patients with rheumatoid arthritis. Extension of a 24 -week randomized, placebo-controlled trial. J Rheumatol 31: 1103-1111, 2004.

65. Araki M, Matsuoka T, Miyamoto K, Kusunoki S, Okamoto T, Murata M, Miyake S, Aranami T and Yamamura T: Efficacy of the anti-IL-6 receptor antibody tocilizumab in neuromyelitis optica: A pilot study. Neurology 82: 1302-1306, 2014.

66. Scott LJ: Tocilizumab: A review in rheumatoid arthritis. Drugs 77: 1865-1879, 2017

67. Smolen JS, Beaulieu A, Rubbert-Roth A, Ramos-Remus C, Rovensky J, Alecock E, Woodworth T and Alten R; OPTION Investigators: Effect of interleukin-6 receptor inhibition with tocilizumab in patients with rheumatoid arthritis (OPTION study): A double-blind, placebo controlled, randomised trial. Lancet 371: 987-997, 2008.

68. Maini RN, Taylor PC, Szechinski J, Pavelka K, Bröll J, Balint G, Emery P, Raemen F, Petersen J, Smolen J, et al: Double-blind randomized controlled clinical trial of the interleukin- 6 receptor antagonist, tocilizumab, in European patients with rheumatoid arthritis who had an incomplete response to methotrexate. Arthritis Rheum 54: 2817-2829, 2006.

69. Yip RML and Yim CW: Role of interleukin-6 inhibitors in the management of rheumatoid arthritis. J Clin Rheumatol: 2019, doi: 10.1097/RHU.0000000000001293 (Online ahead of print).

70. Park JY and Pillinger MH: Interleukin-6 in the pathogenesis of rheumatoid arthritis. Bull NYU Hosp Jt Dis 65 (Suppl 1): S4-S10, 2007.

71. Conigliaro P, Triggianese P, De Martino E, Fonti GL, Chimenti MS, Sunzini F, Viola A, Canofari C and Perricone R: Challenges in the treatment of rheumatoid arthritis. Autoimmun Rev 18: 706-713, 2019.

72. Emery P, Pope JE, Kruger K, Lippe R, DeMasi R, Lula S and Kola B: Efficacy of monotherapy with biologics and JAK inhibitors for the treatment of rheumatoid arthritis: A systematic review. Adv Ther 35: 1535-1563, 2018.

73. Gaffen SL: The role of interleukin-17 in the pathogenesis of rheumatoid arthritis. Curr Rheumatol Rep 11: 365-370, 2009.

74. Kasperkovitz PV, Verbeet NL, Smeets TJ, van Rietschoten JG, Kraan MC, van der Pouw Kraan TC, Tak PP and Verweij CL: Activation of the STAT1 pathway in rheumatoid arthritis. Ann Rheum Dis 63: 233-239, 2004.

75. Hodes GE, Ménard C and Russo SJ: Integrating Interleukin-6 into depression diagnosis and treatment. Neurobiol Stress 4: $15-22,2016$. 
76. Khandaker GM, Pearson RM, Zammit S, Lewis G and Jones PB: Association of serum interleukin 6 and C-reactive protein in childhood with depression and psychosis in young adult life: A population-based longitudinal study. JAMA Psychiatry 71: $1121-1128,2014$

77. Koo JW and Duman RS: Evidence for IL-1 receptor blockade as a therapeutic strategy for the treatment of depression. Curr Opin Investig Drugs 10: 664-671, 2009.

78. Raison CL, Capuron L and Miller AH: Cytokines sing the blues: Inflammation and the pathogenesis of depression. Trends Immunol 27: 24-31, 2006.

79. Steptoe A, Hamer M and Chida Y: The effects of acute psychological stress on circulating inflammatory factors in humans: A review and meta-analysis. Brain Behav Immun 21: 901-912, 2007.

80. Liu H, Luiten PG, Eisel UL, Dejongste MJ and Schoemaker RG: Depression after myocardial infarction: TNF- $\alpha$-induced alterations of the blood-brain barrier and its putative therapeutic implications. Neurosci Biobehav Rev 37: 561-572, 2013.

81. Abbott R, Whear R, Nikolaou V, Bethel A, Coon JT, Stein K and Dickens C: Tumour necrosis factor- $\alpha$ inhibitor therapy in chronic physical illness: A systematic review and meta-analysis of the effect on depression and anxiety. J Psychosom Res 79: 175-184, 2015.

82. Kamel KM, Gad AM, Mansour SM, Safar MM and Fawzy HM Venlafaxine alleviates complete Freund's adjuvant-induced arthritis in rats: Modulation of STAT-3/IL-17/RANKL axis. Life Sci 226: 68-76, 2019.

83. Song L, Quan X, Su L, Wang K, Wang H, Wu L, Chen C, Li S, Xiang W, Chen L and Zhou J: Inflammation and behavioral symptoms in preoperational glioma patients: Is depression, anxiety, and cognitive impairment related to markers of systemic inflammation? Brain Behav 10: e01771, 2020.

84. Lu DY, Leung YM and Su LP: Interferon- $\alpha$ induces nitric oxide synthase expression and haem oxygenase-1 down-regulation in microglia: Implications of cellular mechanism of IFN- $\alpha$-induced depression. Int J Neuropsychopharmacol 16: 433-444, 2013.
85. Carboni 1, McCarthy DJ, Delafont B, Filosi M, Ivanchenko E, Ratti E, Learned SM, Alexander R and Domenici E: Biomarkers for response in major depression: Comparing paroxetine and venlafaxine from two randomised placebo-controlled clinical studies. Transl Psychiatry 9: 182, 2019.

86. Simen BB, Duman CH, Simen AA and Duman RS: TNFalpha signaling in depression and anxiety: Behavioral consequences of individual receptor targeting. Biol Psychiatry 59: 775-785, 2006.

87. Telfer JF and Brock JH: Proinflammatory cytokines increase iron uptake into human monocytes and synovial fibroblasts from patients with rheumatoid arthritis. Med Sci Monit 10: BR91-BR95, 2004.

88. Jenkins JK, Hardy KJ and McMurray RW: The pathogenesis of rheumatoid arthritis: A guide to therapy. Am J Med Sci 323: 171-180, 2002.

89. De Simone V, Franzè E, Ronchetti G, Colantoni A, Fantini MC, Di Fusco D, Sica GS, Sileri P, MacDonald TT, Pallone F, et al: Th17-type cytokines, IL- 6 and TNF- $\alpha$ synergistically activate STAT3 and NF-kB to promote colorectal cancer cell growth. Oncogene 34: 3493-3503, 2015.

90. Kato H, Endres J and Fox DA: The roles of IFN- $\gamma$ versus IL-17 in pathogenic effects of human Th17 cells on synovial fibroblasts. Mod Rheumatol 23: 1140-1150, 2013.

91. Campbell J, Ciesielski CJ, Hunt AE, Horwood NJ, Beech JT, Hayes LA, Denys A, Feldmann M, Brennan FM and Foxwell BM: A novel mechanism for TNF-alpha regulation by p38 MAPK: Involvement of NF-kappa B with implications for therapy in rheumatoid arthritis. J Immunol 173: 6928-6937, 2004.

92. De Cesaris P, Starace D, Riccioli A, Padula F, Filippini A and Ziparo E: Tumor necrosis factor-alpha induces interleukin-6 production and integrin ligand expression by distinct transduction pathways. J Biol Chem 273: 7566-5671, 1998.

This work is licensed under a Creative Commons Attribution-NonCommercial-NoDerivatives 4.0 International (CC BY-NC-ND 4.0) License. 